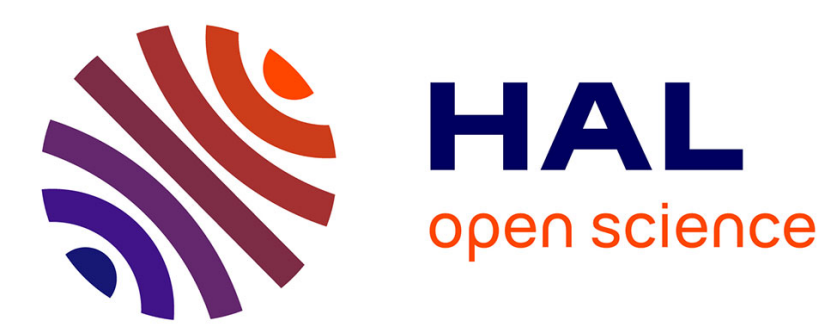

\title{
Using Compact Thermal Modelling for the investigation of a cooling system dysfunction applied to a power module with double sided cooling
}

\author{
Anais Cassou, Patrick Tounsi, Jean-Pierre Fradin
}

\section{- To cite this version:}

Anais Cassou, Patrick Tounsi, Jean-Pierre Fradin. Using Compact Thermal Modelling for the investigation of a cooling system dysfunction applied to a power module with double sided cooling. MIXDES 2019, Jun 2019, Rzeszow, Poland. 10.23919/MIXDES.2019.8787192 . hal-02613604

\section{HAL Id: hal-02613604 \\ https://hal.laas.fr/hal-02613604}

Submitted on 20 May 2020

HAL is a multi-disciplinary open access archive for the deposit and dissemination of scientific research documents, whether they are published or not. The documents may come from teaching and research institutions in France or abroad, or from public or private research centers.
L'archive ouverte pluridisciplinaire HAL, est destinée au dépôt et à la diffusion de documents scientifiques de niveau recherche, publiés ou non, émanant des établissements d'enseignement et de recherche français ou étrangers, des laboratoires publics ou privés. 


\title{
Using Compact Thermal Modelling for the investigation of a cooling system dysfunction applied to a power module with double sided cooling
}

\author{
Anaïs Cassou* ${ }^{1}$, Patrick Tounsi ${ }^{1}$ and Jean-Pierre Fradin ${ }^{2}$
}

${ }^{1}$ CNRS, LAAS, 7 avenue du Colonel Roche, Univ. De Toulouse, INSA, LAAS, F-31400 Toulouse, France

${ }^{2}$ ICAM, site de Toulouse, 75 avenue de Grande Bretagne, 31076 Toulouse Cedex 3, France

* Email: $\underline{\text { anais.cassou@laas.fr }}$

\begin{abstract}
Using our innovative Compact Thermal Model (CTM) methodology, in this paper, we demonstrate how CTM can help to predict junction temperature in case of a cooling dysfunction. We applied our method on a complex power module with double sided cooling to highlight the efficiency of this modelling tool.
\end{abstract}

Keywords - compact thermal modelling, thermal coupling, power module, double sided cooling

\section{INTRODUCTION}

Current automotive applications in power electronics tend to increase the integration of power modules with key objectives of compactness and reliability. In this context, CTM are fast and efficient modelling tools for the study of the thermal dissipation of these systems in order to ensure the thermal management of the devices. Indeed, the devices junction temperatures are important information because they are used to estimate the level of cooling required for the proper functioning of the components. CTM will be here used to investigate cases of a cooling system dysfunction.

One can find in CTM literature two main strategies of compact thermal modelling for power modules: model order reduction from $3 \mathrm{D}$ numerical simulations with a loss of physical sense [1]-[3] and CTM parametrized with structural and material properties [4]-[6]. The originality of the presented CTM methodology is to extract models with a physical meaning while taking into account the thermal couplings. Moreover, thermal resistances are self-adaptive according to boundary conditions.

In this paper, the CTM methodology is applied on a power module with double sided cooling. This power module has been developed by the French Institute of Technology Antoine de Saint Exupéry in collaboration with $a \mathrm{PSI}^{3 \mathrm{D}}$ for an automotive application [7]. It consists of an inverter leg composed of two IGBTs and two diodes in configuration of High Side (HS) and Low Side (LS) switches (fig. 1). Notations used for the devices are T_LS: LS IGBT, D_LS: LS diode, T_HS: HS IGBT and D_HS:
HS diode. This module is double sided cooled (fig.2) [8] with glycol water. The coolant flow rate can be changed to simulate nominal and degraded operating conditions of the module as for example a case of a pump defect.

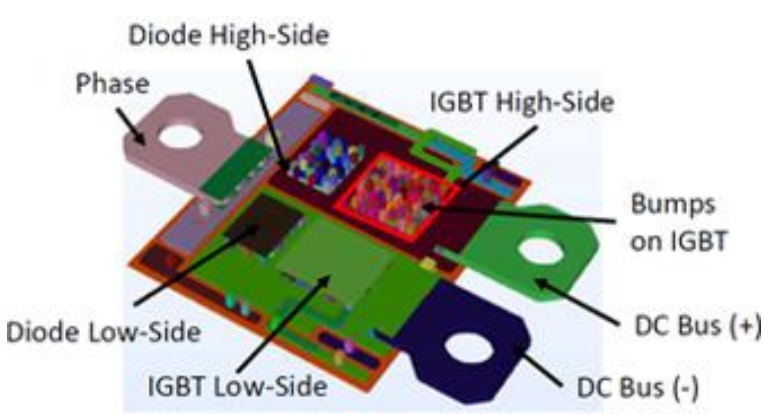

Fig.1. 3D model of the power module

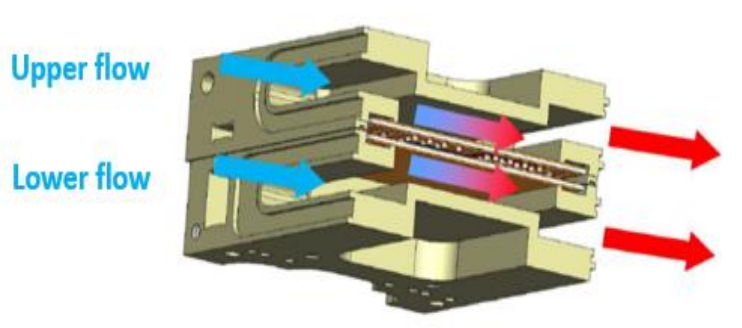

Fig. 2. Power module with double sided cooling

The aim of this work is to generate accurate and low consuming time thermal models for power electronic systems designers for any module topology and any type of cooling system.

In this paper, we extract the CTM of the studied power module from a database built with 3D thermal simulations using a Computational Fluid Dynamics software 
(6SigmaET). The CTM is used to simulate its thermal behavior for different cooling configurations. The extracted model takes into account the thermal coupling between the components and it is auto-adaptive to any boundary condition change. The results are compared with 3D thermal fluidic simulations.

\section{EXTRACTION OF THE CTM}

\section{A. Thermal coupling}

The thermal model is defined for four heat sources considering the non-symmetrical structure where HS switches and LS switches are located on a same Active Metal Brazing (AMB) substrate (fig.3). The aim is to estimate the mutual heating between the chips using the Optimal Thermal Coupling Point (OTCP) method [9].

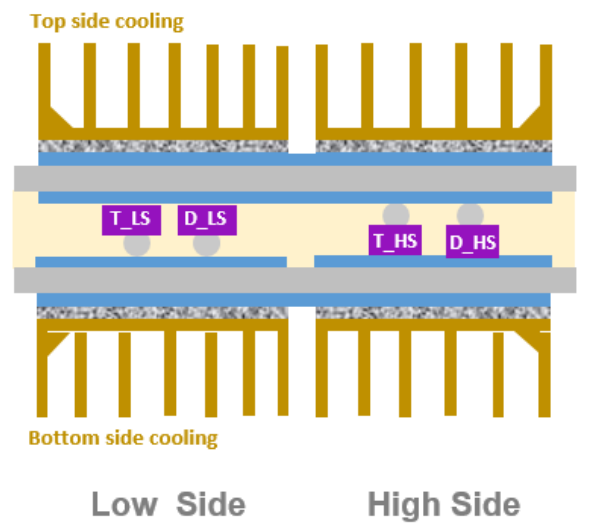

Fig. 3. Schematic view of the power module

The OTCP methodology is applied for each activated heat source at once in order to characterize its thermal dissipation in the module (fig.4). For example, if T_LS is the only device turned ON, four isothermal surfaces can be defined at the same temperature than the inactive sources D_LS, T_HS and D_HS.

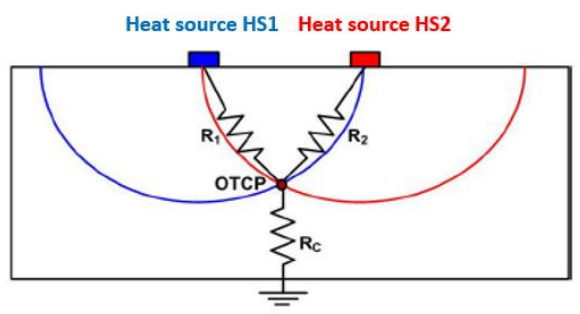

Fig. 4. Illustration of the Optimal Thermal Coupling Point (OTCP) for two heat sources

For this case, a record of the sources temperatures is made from 3D thermal fluidic simulations using 6SigmaET software. The same process is repeated for each heat source and for 9 configurations of the cooling system so-called "test cases" by changing the coolant flow rate at the top and bottom sides. The temperatures levels due to the proximity with the heat source defines the nodes of the equivalent electrical network. Then the thermal resistances are calculated with steady 3D temperatures and fluxes. Consequently, they are not based on geometry and materials properties. The thermal resistances of the equivalent electrical network are defined as the connection between OTCP and not to nodes in the structure.

\section{B. The CTM structure}

The CTM is extracted for the power module, with double sided cooling, considering four heat sources (two IGBTs and two diodes) and two cooling paths with the temperatures of the coolant as boundary conditions. A thermal model is defined for each heat source, from the junction to the cooling system, with resistances in series between each OTCP representing the thermal interaction between the active chip and the others (fig.5).

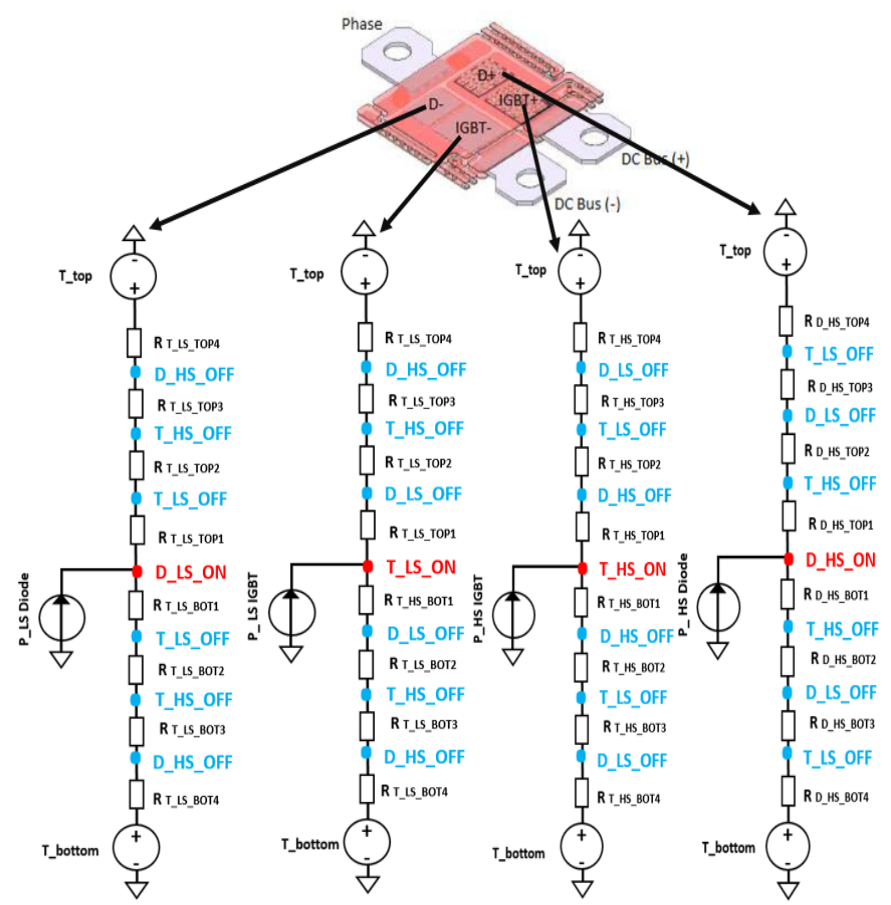

Fig. 5. The CTM structure for four heat sources

Finally, the junction temperature of each source is calculated by adding the temperature due to the activation of the source itself and the temperature rise linked to the thermal coupling between heat sources [10]. For example, the junction temperature of the LS IGBT is equal to:

$$
\mathrm{Tj}_{\mathrm{T} \_L}=\mathrm{T} \_L S \_O N+\sum_{i=3} \mathrm{~T}_{-} L S \_O F F(\mathrm{i})
$$

with T_LS_ON: temperature of LS IGBT when it is the only device turned $\mathrm{ON}\left[{ }^{\circ} \mathrm{C}\right], \mathrm{T}_{-} \mathrm{LS} \_\mathrm{OFF}$ : temperature of inactivate LS IGBT when another chip is switched $\mathrm{ON}\left[{ }^{\circ} \mathrm{C}\right]$ 


\section{Estimation of heat flux ratios}

Once the CTM structure is defined, the heat flux in the two branches from the junction to the top side cooling $\left(\mathrm{P}_{\text {top }}\right)$ and to the bottom side cooling $\left(\mathrm{P}_{\text {bottom }}\right)$ have to be estimated to calculate the thermal resistances values. The objective is to determine the heat flux ratios $\mathrm{P}_{\text {top }} / \mathrm{P}_{\text {tot }}$ and $\mathrm{P}_{\text {bottom }} / \mathrm{P}_{\text {tot }}$ with $\mathrm{P}_{\text {tot }}=\mathrm{P}_{\text {top }}+\mathrm{P}_{\text {bottom }}$ for any cooling configuration with a total coolant flow rate of $8 \mathrm{l} / \mathrm{min}$.

The dissipated powers through the two branches of a CTM are directly linked to the cooling configuration i.e. the coolant flow rate. Using the information providing by the test cases, a relation is defined between the flow rate at the top side cooling flow_TS, the flow rate at the bottom side flow_BS and the ratios of dissipated powers $\mathrm{P}_{\text {top }} / \mathrm{P}_{\text {tot }}$ and $\mathrm{P}_{\text {bottom }} / \mathrm{P}_{\text {tot }}$ (fig.6).

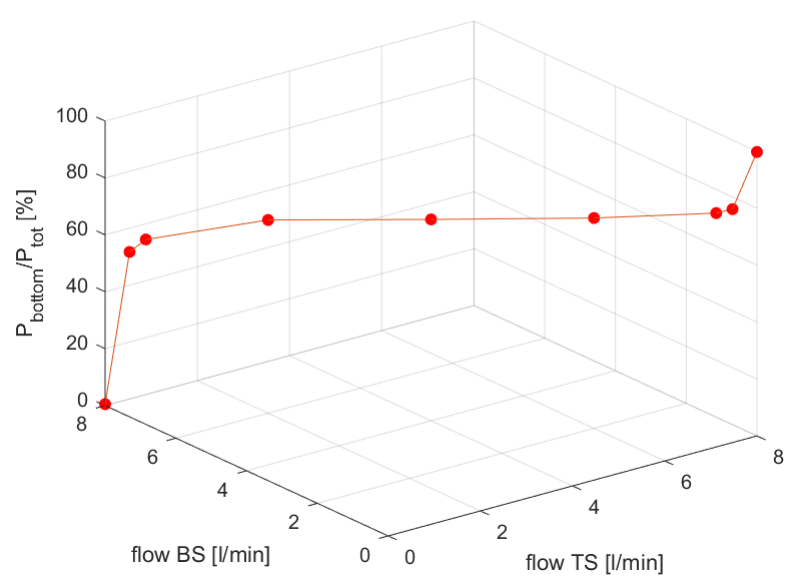

Fig. 6. Heat flux ratio $\mathrm{P}_{\text {bottom }} / \mathrm{P}_{\text {tot }}$ versus flow rates at the bottom and top side cooling for the CTM of HS IGBT

One can now choose a desired configuration to test the power module under nominative operating conditions to degraded modes i.e. the liquid flow rate at the top side or bottom side cooling can be reduced to simulate a cooling system dysfunction.

\section{Variations laws of thermal resistances}

One main interest of this CTM methodology concerns the thermal resistances variations. Their values are not fixed but they vary according to boundary conditions change.

Knowing the temperatures of the components and the dissipated powers, the thermal resistances are calculated for each test cases with the expression:

$$
R_{t h}=\frac{\Delta T}{P} \quad\left[\mathrm{~K} . \mathrm{W}^{-1}\right]
$$

Then a variation law is defined for each thermal resistances versus the heat flux ratio using a spline data interpolation (fig.7). A piecewise fitting is well adapted in this case because it is not possible to find a global law that describes the thermal behavior which is quite complex at the limit cases of degraded functioning.

In the case of a cooling system dysfunction, 3D thermal phenomena have to be considered like the spreading of the heat flux in the structure due to the reduced efficiency of the cooling. In some cases, furthest chips from the heat source can be more heated. Consequently, it affects the temperatures ranks previously defined and so the nodes order of the the CTM is changed. Control laws of thermal resistances assigns negative sign to some resistances take into account this 3D thermal effect.

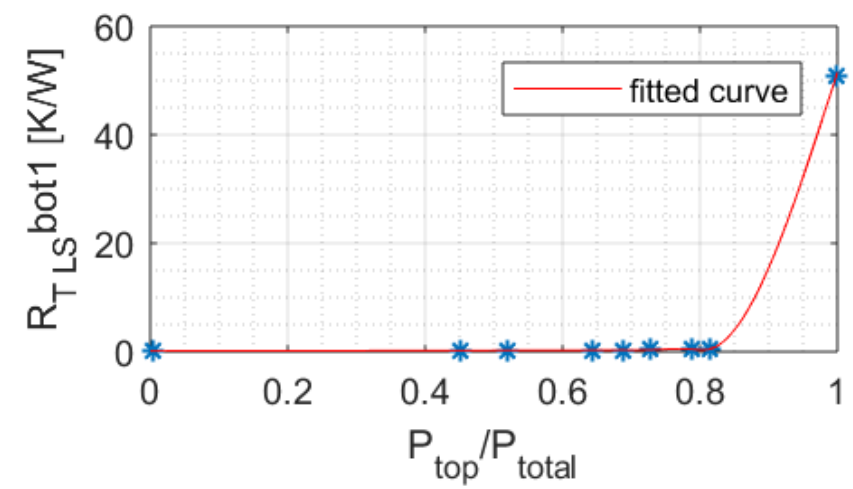

(a)

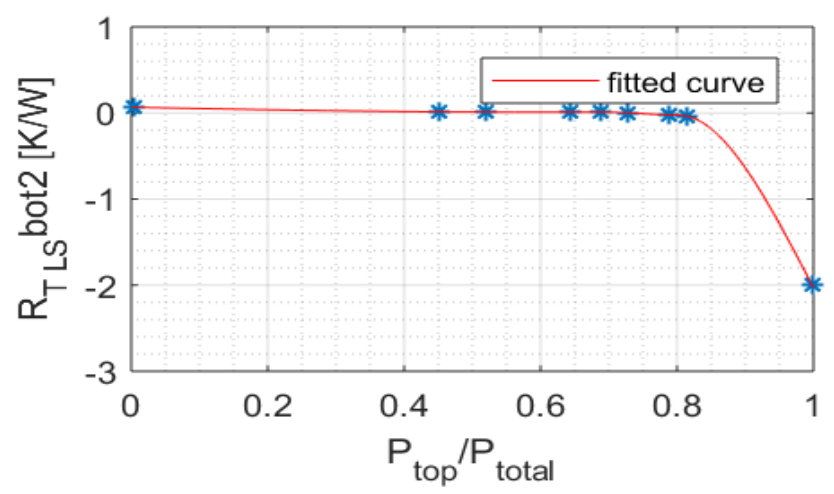

(b)

Fig.7. Variation laws of the thermal resistances (a) $R_{\text {TLS bot1 }}$ and (b) $R_{\text {TLS }}$ bot2 of the CTM of LS IGBT

Therefore, the extracted CTM considers the multiple paths of $3 \mathrm{D}$ heat flux depending on the cooling system configuration and it is auto-adaptive in respect of boundary conditions with a self-adaptation of the thermal resistances. 


\section{APPLICATION CASES}

In this part, the extracted CTM is used to simulate a cooling system defect as the obstruction of cooling fins and therefore the coolant flow rate at the bottom or top side cooling is reduced. The extracted CTM will be compared with 3D thermal simulations using software 6SigmaET software. For the application cases, all devices dissipate powers (Table 1).

Table 1. Dissipated powers

\begin{tabular}{|c|c|}
\hline Heat sources & Dissipated power [W] \\
\hline HS IGBT & 682 \\
\hline HS diode & 146 \\
\hline LS IGBT & 682 \\
\hline LS diode & 146 \\
\hline
\end{tabular}

The cooling configuration is parametrized, for example, with the upper coolant flow rate set at $61 / \mathrm{min}$ and lower flow rate set at $2 \mathrm{l} / \mathrm{min}$. The heat flux ratios of each CTM branches are deduced using the interpolation law previously defined (fig.8). Then each thermal resistance value selfadapts according to the calculated heat flux ratio.

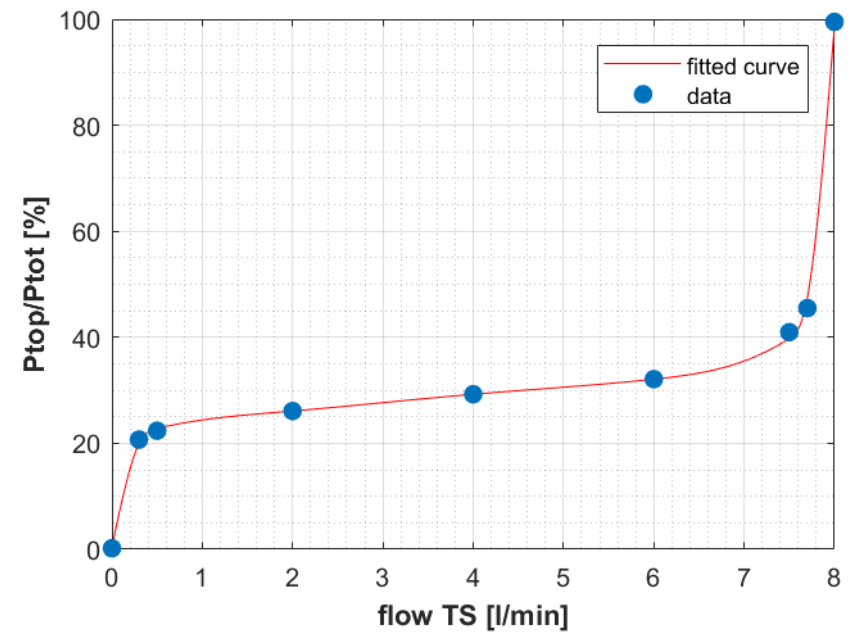

Fig.8. Heat flux ratio $\mathrm{P}_{\text {top }} / \mathrm{P}_{\text {tot }}$ versus coolant flow rate at the top side cooling flow_TS for the CTM of HS IGBT

The junction temperatures calculated with the CTM method will be are compared with 3D thermal fluidic simulations results for several cooling system configurations (Table 2) using the relative error criterion:

$$
\varepsilon_{r}=100 \frac{\left|T_{j C T M}-T_{j 3 D}\right|}{T_{j 3 D}-T_{\text {ref }}} \quad[\%]
$$

with $\mathrm{T}_{\mathrm{j} \text { стм }}$ : junction temperature with $\mathrm{CTM}\left[{ }^{\circ} \mathrm{C}\right], \mathrm{T}_{\mathrm{j} 3 \mathrm{D}}$ : junction temperature with $3 \mathrm{D}$ model $\left[{ }^{\circ} \mathrm{C}\right], \mathrm{T}_{\text {ref: }}$ cooling liquid temperature $\left[{ }^{\circ} \mathrm{C}\right]$
Table 2. Results comparison

\begin{tabular}{|c|c|c|c|c|c|c|c|c|c|}
\hline \multirow[b]{2}{*}{ device } & \multicolumn{3}{|c|}{$\begin{array}{c}\text { Top side } 41 / \mathrm{min} \\
\text { Bottom side } 41 / \mathrm{min}\end{array}$} & \multicolumn{3}{|c|}{$\begin{array}{c}\text { Top side } 61 / \mathrm{min} \\
\text { Bottom side } 21 / \mathrm{min}\end{array}$} & \multicolumn{3}{|c|}{$\begin{array}{c}\text { Top side } 2 \mathrm{l} / \mathrm{min} \\
\text { Bottom side } 61 / \mathrm{min}\end{array}$} \\
\hline & $\begin{array}{c}\mathbf{T}_{\mathbf{j C T M}} \\
{\left[{ }^{\circ} \mathbf{C}\right]}\end{array}$ & $\begin{array}{l}\mathbf{T}_{\mathbf{j 3 D}} \\
{\left[{ }^{\circ} \mathbf{C}\right]}\end{array}$ & $\begin{array}{c}\varepsilon_{\mathrm{r}} \\
{[\%]}\end{array}$ & $\begin{array}{c}\mathbf{T}_{\text {jCTM }} \\
{\left[{ }^{\circ} \mathbf{C}\right]}\end{array}$ & $\begin{array}{r}\mathbf{T}_{\mathbf{j 3 D}} \\
{\left[{ }^{\circ} \mathbf{C}\right]}\end{array}$ & $\begin{array}{r}\varepsilon_{\mathrm{r}} \\
{[\%]}\end{array}$ & $\begin{array}{c}\mathbf{T}_{\text {jCTM }} \\
{\left[{ }^{\circ} \mathbf{C}\right]}\end{array}$ & $\begin{array}{r}\mathbf{T}_{\mathbf{j 3 D}} \\
{\left[{ }^{\circ} \mathbf{C}\right]}\end{array}$ & $\begin{array}{r}\varepsilon_{\mathrm{r}} \\
{[\%]}\end{array}$ \\
\hline $\begin{array}{c}\text { HS } \\
\text { IGBT }\end{array}$ & 149 & 150 & 1.2 & 154 & 152 & 2.3 & 146 & 145 & 1.3 \\
\hline $\begin{array}{c}\text { HS } \\
\text { diode }\end{array}$ & 102 & 103 & 2.6 & 105 & 104 & 2.6 & 101 & 101 & 0 \\
\hline $\begin{array}{c}\text { LS } \\
\text { IGBT }\end{array}$ & 142 & 142 & 0 & 138 & 138 & 0 & 145 & 144 & 1.3 \\
\hline $\begin{array}{c}\text { LS } \\
\text { diode }\end{array}$ & 99 & 100 & 2.9 & 98 & 97 & 3.1 & 102 & 101 & 2.8 \\
\hline
\end{tabular}

The achieved results by CTM method are validated with a satisfactory accuracy compared to $3 \mathrm{D}$ thermal simulations with a maximal relative error of $3.1 \%$ for different cooling configurations. A future prospect to improve the extracted CTM will be to determine the temperature at the complex interface between AMB substrate and the coolant.

\section{CONCLUSION}

The presented CTM methodology is used to simulate a power module with double sided cooling for automotive applications. The use of CTM is an efficient tool to model complex structure with a reduced calculation time compared to 3D thermal simulators. Moreover, the accuracy of the CTM is taking into account the thermal coupling between the components and it is auto-adaptive for any boundary conditions change. The thermal CTM methodology developed at LAAS-CNRS has been improved to adapt to new power module topologies. We showed that the developed CTM can well describe extreme degraded functioning which implies the huge variation of the heat flux close to the physical limits of the coolant flow rate. In the final paper, we will give additional results using the model in the application case. Future works will deal with transient phenomena consideration.

\section{ACKNOWLEDGMENT}

The authors would like to thank $a \mathrm{PSI}^{3 \mathrm{D}}$ company and the French Institute of Technology Antoine de Saint Exupéry for providing us data on the power module and ICAM for the results of $3 \mathrm{D}$ thermal simulations. 


\section{REFERENCES}

[1] D. Celo et al., "The creation of compact thermal models of electronic components using model reduction," in IEEE Transactions on Advanced Packaging, vol. 28, no. 2, pp. 240251, May 2005.

[2] E. Monier-Vinard, V. Bissuel, C. Dia and O. Daniel, "Delphi style compact modeling by means of genetic algorithms of system in Package devices using composite sub-compact thermal models dedicated to model order reduction," 13th InterSociety Conference on Thermal and Thermomechanical Phenomena in Electronic Systems, San Diego, CA, 2012, pp. 1170-1178.

[3] H. B. Aissia, J. Jay, S. Xin and R. Knikker, "Thermal Reduced Order Model for an Electronic Power Module," 2018 24rd International Workshop on Thermal Investigations of ICs and Systems (THERMINIC), Stockholm, 2018, pp. 1-4.

[4] Z. Zhou, P. M. Holland and P. Igic, "Compact thermal model of a three-phase IGBT inverter power module," 2008 26th International Conference on Microelectronics, Nis, 2008, pp. 167-170.

[5] J. J. Rodriguez et al., "Thermal component models for electro thermal analysis of multichip power modules," Conference Record of the 2002 IEEE Industry Applications Conference. 37th IAS Annual Meeting (Cat. No.02CH37344), Pittsburgh, PA, USA, 2002, pp. 234-241 vol.1.

[6] M. Shahjalal, H. Lu and C. Bailey, "Electro-thermal modelling of multichip power modules for high power converter application," 2017 18th International Conference on Electronic Packaging Technology (ICEPT), Harbin, 2017, pp. 940-945.

[7] J.-P. Fradin, D. Elzo, S. Sanchez, C. Cadile, M. Balzer, P.-A. Colombie, "Innovative power modules: junction temperature estimation", $12 \mathrm{~h}$ European ATW on Micropackaging and Thermal Management (IMAPS), La Rochelle, France, 2017.

[8] J. Favre, J.-M. Reynes, J.-P. Fradin, C. Cadile, S. Sanchez, D. Elzo and E. Marcault, "Double side cooled Electronic Power Module", PCIM Europe 2017; International Exhibition and Conference for Power Electronics, Intelligent Motion, Renewable Energy and Energy Management, Nuremberg, Germany, 2017, pp. 1-8.

[9] W. Habra, P. Tounsi, J.-M. Dorkel, "Advanced compact thermal model using VHDL-AMS", 12th International Workshop on Thermal Investigations of ICS and Systems (THERMINIC), Nice, France, 2006, pp.225-228.

[10] W. Habra, P. Tounsi, F. Madrid, Ph. Dupuy, C. Barbot and, J.M. Dorkel, "A New Methodology for Extraction of Dynamic Compact Thermal Models",13th International Workshop on Thermal Investigations of ICs and Systems (THERMINIC), Budapest, 2007, pp. 141-144. 